\title{
METODOLOGIA DE AVALIAÇÃo DE DANOS CORPORAIS EM PERÍCIAS MÉDICAS
}

\section{METHODOLOGY FOR THE EVALUATION OF BODILY HARM BY MEDICAL EXPERT WITNESSES}

\section{Weliton Barbosa Santos}

Especialista em Medicina Legal e Perícias Médicas, Faculdade UNIMED (Brasil). Possui máster em Medicina Forense pela Universidade de Valencia (2005), é especialista em Medicina Legal e Perícias Médicas (2007). É médico perito e assistente técnico nos âmbitos do Direito Civil, Direito do Trabalho e Direito Penal e médico endoscopista. Professor na Fundação UNIMED nos cursos de Perícias Médicas - Avaliação do Dano Corporal e Perícias Securitárias e de Medicina Lega. Professor de Medicina Legal no Curso de Direito da Faculdade Promove. Contato: welitonbs@gmail.com.

\section{Wagner Fonseca Moreira da Silva}

Graduação em Medicina pela Universidade Federal de Minas Gerais (1993), Máster em Medicina Forense Universitat de Valencia (2005), pós-graduação em Avaliação do Dano Corporal em Direito Civil (2007), Mestrado em Ciências Forenses (2009/2012). Mestre em Ciências Forenses e Médico Legista da Secretaria de Defesa Social/MG. Coordenador e professor do curso de pós-graduação em Perícia Médica da Faculdade Unimed, exerce atualmente suas atividades como Coordenador de Perícias Médicas do Hospital da Polícia Civil/MG e coordenador do Núcleo de Educação Permanente da Superintendência de Perícia Médica e Saúde Ocupacional da SEPLAG/MG.

\section{Puarte Nuno Vieira}

Professor catedrático da Faculdade de Medicina da Universidade de Coimbra.

É Presidente do Conselho Europeu de Medicina Legal, Presidente do Conselho Forense Consultivo do Procurador do Tribunal Penal Internacional, Presidente da Rede Ibero-Americana de Instituições de Medicina Legal e Ciências Forenses, Presidente da Associação Portuguesa de Avaliação do Dano Corporal, Presidente da Thematic Federation on Legal and Forensic Medicine da União Europeia de Médicos Especialistas e Vice-Presidente da Confederação Europeia de Especialistas em Avaliação e Reparação do Dano Corporal. 


\section{RESUMO}

As perícias médicas de Avaliação de Danos Corporais no Brasil, para efeito de indenizações, necessitam de uma harmonização de conceitos e metodologia. $\mathrm{O}$ artigo apresenta a metodologia e conceitos utilizados nos países da comunidade europeia que seguem as indicações da Confederação Europeia de Especialistas em Avaliação e Reparação do Dano Corporal (CEREDOC), particularmente em Portugal. São descritos e analisados os clássicos critérios de nexo de causalidade ou imputabilidade médica, assim como os elementos do dano suscetíveis de serem objeto de indenização, designados como parâmetros de danos temporários e permanentes. Na sequência são realizadas reflexões a respeito da necessária harmonização destas avaliações, que devem conter descrições de forma clara, objetiva e pormenorizada do dano corporal, identificar os conceitos e instrumentos usados na avaliação, fundamentando-a, sempre que possível, na consulta de documentos clínicos. Deve, ainda, conter a análise e interpretação do dano corporal sofrido pela pessoa, de modo a permitir a sua compreensão por todas as partes envolvidas. Ao final ressalta-se a importância de cursos de formação para Médicos Peritos e demais especialistas clínicos que tenham interesse nesta matéria, expectativa que vem sendo concretizada pelos esforços, dedicação e solicitude de diversos profissionais de ambos os países e graças ao apoio científico de diversas entidades portuguesas, nomeadamente a Área de Ciências Médico-Legais da Universidade de Coimbra, o Instituto Nacional de Medicina Legal de Portugal, a Associação Portuguesa de Avaliação do Dano Corporal e o Centro de Estudos de Pós-Graduação em Medicina Legal, concretizados em parceria com diversas instituições acadêmicas brasileiras.

Palavras-chave: Dano Corporal. Perícia Médica. Nexo de causalidade. Avaliação médicolegal. Indenização.

\section{ABSTRACT}

Medical and forensic evaluations performed in Brazil for indemnity purposes need a necessary harmonization of concepts and methodology. This article presents the methodology and concepts used by the European community which follows the indications of the European Confederation of Specialists in Assessment and Repair of Bodily Injury (CEREDOC), particularly in Portugal. The classic criteria of causality or medical imputability is described 
and analyzed, as well as the elements of damage that may be subject to compensation, designated as temporary and permanent damage parameters. Following are reflections on the necessary harmonization of these assessments, which should contain clear, objective and detailed descriptions of the body damage, identify the concepts and instruments used in the assessment, based, whenever possible, on the consultation of clinical documents. It must also contain the analysis and interpretation of the bodily harm suffered by the person, in order to allow its understanding by all the parties involved. Finally, the importance of training courses for Medical Expert Witness and other clinical specialists who have an interest in this matter is emphasized. It is an expectation that has been achieved through the efforts, dedication and solicitude of professional from both countries and thanks to the partnerships established between Portuguese and Brazilian institutions.

Keyword: Bodily harm. Medical expertise. Causality nexus. Forensic evaluation. Reparation. 


\section{INTRODUÇÃO}

No desenvolvimento da sua atividade, o médico perito brasileiro depara-se com uma quase ausência de normas quanto à realização de perícias, no âmbito do Direito Civil e do Direito do Trabalho, para efeito de atribuição de indenização. E, quando essas normas existem, verifica-se o frequente não cumprimento das mesmas.

Trata-se de fato que pode ser gerador de prejuízos para a boa administração da Justiça e para a devida satisfação dos direitos e necessidades das vítimas. Por isso muito médicos peritos decidiram investir na sua formação nesta área em Portugal. Escolheram este país não só pelo fato da língua ser a mesma, mas porque, para além de muitas similitudes ao nível das questões legais nesta matéria, existe uma reconhecida experiência na avaliação do dano corporal, que passa pela existência de normas e modelos de avaliação médico-legal bem desenvolvidos e implementados (SILVA, 2012).

O contato com a realidade médico-legal portuguesa tem proporcionado a estes médicos novas perspetivas relativamente ao que desejavam fosse a atividade de avaliação do dano corporal no Brasil. É nessa sequência que surge esse artigo, o qual pretende apresentar uma análise e reflexão sobre a importância da harmonização das avaliações do dano corporal em Direito Civil e do Trabalho.

Nas últimas décadas do século XX, a entrada dos chamados "países em desenvolvimento" no processo de motorização maciça fez disparar os números de sinistralidade rodoviária. A combinação de um aumento rápido da frota de veículos, os recursos limitados para a segurança, bem como a manutenção das estradas, tem produzido consequências dramáticas em termos de sinistralidade, sobretudo em regiões como a África, Ásia e América Latina. Efetivamente, a redução das taxas de sinistralidade observadas nos anos oitenta, em alguns países desenvolvidos, foi insignificante face ao aumento desta sinistralidade nos países em desenvolvimento (ESTEVAN, 2001), e o número de indivíduos com sequelas por acidente de trânsito tem aumentado significativamente (MARIN \& QUEIROZ, 2000).

O panorama dos acidentes de trânsito em 2005, segundo Jorge e Koizumi (2007), reflete uma taxa de 228 veículos/100 mil habitantes, uma taxa de 208,1 acidentes com vítimas/100 mil habitantes, uma taxa de 19,4 óbitos/100 mil habitantes e uma taxa de internamento hospitalar de 64,1 pacientes/mil habitantes. Os registos hospitalares totalizaram cerca de 160.000 internamentos por ano decorrentes de acidentes de viação (JORGE \& KOIZUMI, 2007). 
Os acidentes de trânsito surgiram, assim, como uma verdadeira epidemia, que produz muitas mortes, ferimentos e sequelas, gerando custos financeiros e sociais enormes (MARIN \& QUEIROZ, 2000), e tendo significativas implicações médico-legais e forenses, dada a importância do estudo das lesões e sequelas, bem como do estabelecimento do nexo de causalidade entre o traumatismo e aquelas, seja para efeito de atribuição de sanção penal, seja para efeito de indenização pelo dano corporal resultante (SILVA \& MAGALHÃES, 2011).

Com relação aos acidentes de trabalho a situação não é muito diferente. No Brasil, agravos relacionados ao trabalho correspondem aproximadamente a $25 \%$ das lesões por causas externas atendidas em serviços de emergência e há mais de 70\% dos benefícios acidentários da Previdência Social (CARDOSO et al, 2016).

Silva e Magalhães, 2011, observaram que os os relatórios médico-legais elaborado no IML de Belo Horizonte por motivo de acidente de trânsito, e tendo como objetivo a reparação do dano corporal, são omissos relativamente a aspetos fundamentais que importa que constem, exigindo uma reflexão no sentido de se encontrar um caminho para mudar os procedimentos das avaliações periciais (SILVA \& MAGALHÃES, 2011).

A inexistência de normas específicas para avaliação destes danos corporais, com parâmetros de dano definidos, seguindo-se antes em cada região modelos e metodologias diversas, tende, naturalmente, a conclusões periciais díspares, algumas vezes omissas e outras equivocadas. Sem a necessária harmonização doutrinária nesta questão, vítimas e demais integrantes de uma demanda reparatória pecuniária ficarão sujeitos a deliberações administrativas e decisões judiciais conflitantes. Em outras palavras, não havendo conformidade metodológica nas avaliaçõs periciais, danos corporais similares poderão receber reparação discrepante.

Mas a necessária harmonização das avaliações periciais dos danos corporais não atinge apenas os acidentes de trânsito. A avaliação dos danos corporais é demandada nas mais variadas situações jurídicas, como agressões, reclamações de erro profissional, seguros, previdência, acidentes de trabalho e outras, suscetíveis de uma responsabilização.

Portanto, um exame pericial e seu respectivo relatório elaborados em termos e metodologia adequados poderão contribuir, desde logo, para uma melhor intervenção do perito médico, para um melhor serviço à Justiça e para uma melhor e mais justa satisfação da vítima, visando não só promover a sua saúde, reabilitação, reintegração familiar, social e profissional, mas também a sua dignidade e qualidade de vida e, ainda, minorar na medida do possível os 
danos colaterais que nestes casos afetam sempre as famílias e a comunidade em geral (SILVA \& MAGALHÃES, 2011).

Pertence cada vez mais ao passado a época dos "exames de quesitos", em que as perícias médicas de avaliação dos danos corporais se limitavam a simples respostas a questionamentos mais ou menos numerosos (VIEIRA, 2000).

\begin{abstract}
A especialização em determinada área da medicina não confere, por si só, ao seu titular preparação para atuar como perito. Avaliação de danos corporais exige, necessariamente, preparação médico-legal neste domínio, mais que a simples formação em qualquer especialidade clínica, por melhor que tenha sido, não confere. É provável que alguns médicos que atuam como peritos considerem eventualmente não precisar de tal formação e que rejeitem até a idéia de que quando avaliam danos corporais estão a executar uma peritagem médico-legal. Desconhecem por completo as metodologias e especialidades da peritagem da avaliação do dano corporal e esquecem (ignoram) que acontece medicina legal sempre que um ato médico tem (ou é suscetível de vir a ter) implicações legais, sendo avaliação dos danos corporais um ato médico-legal por excelência. Um ato que, por razões óbvias, não é competência exclusiva do especialista em Medicina Legal, mas que pode ser executado por muitos outros especialistas, de várias áreas clínicas, desde que detentores de preparação adequada (de uma competência) neste dominio (VIEIRA, 2000).
\end{abstract}

Este artigo, de revisão, se propõe a descrever, analisar e discutir uma metodologia de Avaliação de Danos Corporais bem desenvolvida na sequência das reflexões concretizadas pela CEREDOC e implementada em diversos países da comunidade europeia, nomeadamente em Portugal.

Desejamos que este artigo possa se constituir em mais uma pequena semente para promover a mudança necessária.

\title{
2 AVALIAÇÃO DO DANO À PESSOA
}

Avaliar um dano à pessoa é

definir e valorar em termos técnicos e num quadro jurídico determinado as lesões e os elementos do dano susceptíveis de serem objeto de sanção penal e/ou indenização, benefícios fiscais, benefícios sociais etc. (VIEIRA, 2008).

Segundo Geerts (1962, apud Oliveira Sá, 1992, p.17), a indenização de lesões corporais pode ser vista através dos séculos e o código de Hamurabi já tratava desta matéria em alguns artigos.

Historicamente, os danos corporais provocados por terceiros deveriam ser indenizados, uma vez que qualquer perturbação da integridade psicofísica constitui um dano supremo. $\mathrm{O}$ antigo "direito" de vingança, conhecido como Lei de Talião, foi sendo substituído gradualmente até alcançar a reparação integral do dano (MAGALHÃES, 1998). 
A integridade psicofísica da pessoa humana é um valor universalmente reconhecido. Ainda no século XXI a integridade das pessoas continua sendo ameaçada pelos mais variados avanços científicos e tecnológicos criados pelos próprios indivíduos. Visto pela óptica de uma reparação, surge uma disciplina referente ao estudo dos danos corporais com necessidade de adotar uma metodologia que reconheça o status particular do corpo humano e o direito à proteção da integridade psicofísica. Atualmente a compensação financeira dos danos à pessoa parece ser o objetivo de todo procedimento de indenização (LAMBERT-FAIVRE, 2011).

A partir de meados do século XX a avaliação do dano corporal torna-se uma área de intervenção pericial cada vez mais relevante no âmbito da clínica forense. Exames periciais que se limitam à simples respostas de quesitos são cada vez mais vistos como um passado e são substituídas por perícias que adotam uma metodologia e uma filosofia consentânea com o atual estado da arte no domínio da avaliação dos danos corporais dando resposta ao princípio da reparação integral destes danos. A reparação integral do dano, que é um objetivo utópico na maioria dos casos, procura restabelecer tão exatamente quanto possível o equilíbrio destruído pelo dano e recolocar a vítima, às expensas do responsável pela produção do dano, na situação em que esta se encontraria se o fato produtor das lesões não tivesse ocorrido. Deve-se ter em mente que a avaliação de danos à pessoa não é uma tarefa fácil (VIEIRA \& QUINTERO, 2008):

Peritar é estudar, entender, depois descrever para fazer compreender. Assim a perícia preserva toda a nobreza e permanece como os demais campos da medicina, não apenas uma técnica, mas especialmente uma arte (LUCAS, 2009).

Para proceder a um exame pericial que permita a avaliação do dano à pessoa os médicos peritos devem pronunciar sobre o nexo de causalidade, estimar a data de consolidação médicolegal e definir os parâmetros do dano constando as incapacidades temporárias e permanentes; elaborando um relatório circunstanciado e justificado de suas conclusões médico-legais (VIEIRA \& QUINTERO, 2008).

A essência da avaliação do dano à pessoa é o estudo do nexo de causalidade. Trata-se do estudo da relação de causa e efeito que deve existir entre o dano medicamente constatado e o evento alegado como causador do dano. Há que considerar o estado anterior, "entendido como o estado patológico existente no momento da ocorrência do traumatismo e o resultado que este pode ter no resultado da avaliação perícia.” Estas situações entendidas como concausas, podem aumentar a complexidade do estudo do caso. A falta de homogeneidade na maneira de avaliação dos diversos peritos pode induzir a dificuldades interpretativas e impedir uma correta avaliação do dano (OLIVEIRA; VIEIRA \& CORTE-REAL, 2017). 
No estudo do nexo de causalidade, visto como momento decisivo para toda perícia, compete ao médico perito informar se as lesões observadas são consequência de um determinado evento e se as sequelas que a vítima alega e cuja realidade se constatou estão vinculadas a tais lesões. Os principais equívocos de uma perícia estão relacionados com o estudo do nexo de causalidade. Nesta abordagem é fundamental dissociar o procedimento médico do procedimento jurídico. O procedimento jurídico atribui as consequências do dano constatado ao responsável pelo evento, sendo da competência dos operadores do direito. A causalidade médica é a relação entre a alteração psicofísica diagnosticada em um indivíduo e um determinado fato, ou seja, é o elemento que permite admitir cientificamente a existência de uma ligação entre um evento alegado e um estado patológico diagnosticado (VIEIRA \& QUINTERO, 2008).

Esta tarefa é do médico perito. O estudo do nexo de causalidade é a explicação que pode ser simples ou bastante complexa dos mecanismos fisiopatológicos que permitem as lesões iniciais gerarem alterações temporárias ou permanentes, apesar dos tratamentos realizados (VIEIRA \& QUINTERO, 2008). Os critérios incialmente propostos e definidos por Muller e Cordonier (1925), foram reagrupados de maneira mais didática por Camille Simonin.

Os critérios para o estudo do nexo de causalidade ou imputabilidade médica são a expressão médico-legal indispensável de causa e efeito que deve existir entre o dano e o traumatismo. Para admitir que um traumatismo seja a causa geradora de uma alteração de integridade psicofísica sete condições devem ser analisadas:

1. Natureza adequada do traumatismo

2. Natureza adequada da afecção traumática

3. Adequação entre a sede do traumatismo e a sede da lesão

4. Encadeamento anatomoclínico

5. Adequação temporal

6. Exclusão da preexistência do dano

7. Exclusão de uma causa estranha ao traumatismo.

A análise destas sete condições é necessária e suficiente para estabelecer o estudo do nexo de causalidade médico-legal (SIMONIN, 1947).

O nexo de causalidade pode ser certo ou hipotético, direto ou indireto, total ou parcial. O nexo é certo quando o evento foi seguramente a causa das lesões e/ou sequelas observadas. $\mathrm{Na}$ eventualidade de dúvida no estabelecimento do nexo de causalidade, esta deve ser explicitada através do nexo de causalidade hipotético, quando na análise não é possível definir 
com segurança, mas ao mesmo tempo não é possível afastar formalmente. O nexo é direto quando as lesões e/ou sequelas, resultam diretamente do evento. $\mathrm{O}$ nexo é indireto quando a relação entre o dano observado e o evento informado mostra uma ligação indireta, por exemplo, uma soropositividade para HIV, na sequência de uma laparotomia para realizar uma esplenectomia e necessidade de uma transfusão sanguínea. O nexo total quando nenhuma outra causa além do evento informado interferiu na alteração de integridade psicofísica analisada. A situação é clara. O nexo de causalidade é parcial, quando existem outras situações ou causas susceptíveis de contribuir para a alteração que foi observada. Existem outras causas que concorrem na evolução. Podem ser analisadas como concausas que podem existir antes do evento, surgir simultaneamente ou manifestarem posteriormente ao evento ocorrido (VIEIRA \& QUINTERO, 2008).

Assim, em alguns casos o dano pode ser entendido como resultado de múltiplas causas entre as quais o traumatismo. Estas situações se definem com nexo parcial, são denominadas de situações de concausalidade ou de causalidade múltipla em que o dano é imputável parcialmente ao traumatismo (SÁ, 1992).

No nexo causal indireto os eventos são supervenientes, surgem posteriormente a ação traumática, geralmente advém de complicações susceptíveis de alterarem o encadeamento anatomoclínico. As situações de concausalidade devem ser discutidas no nexo de causalidade parcial; apesar de considerar o traumatismo a causa imediata da lesão o traumatismo não será o único fator, para alcançar o resultado final. Deve-se tentar esclarecer o estado do indivíduo quando este é vítima de um traumatismo e esta condição representa um desafio para a prática pericial (OLIVEIRA, 2017).

Um tríptico clássico para análise do estado anterior é considerar as seguintes questões:

1. Qual seria a evolução do estado anterior sem o traumatismo?

2. Qual seria a evolução do traumatismo sem o estado anterior?

3. Qual seria a consequência do estado anterior com o traumatismo? (ROUSSEAU, 1983) Entretanto os conhecimentos clínicos atuais frequentemente não permitem prognosticar estes quadros evolutivos, gerando sempre uma dúvida, principalmente em condições de fragilidades naturais relacionadas com a idade, estado gestacional e outros, ou até mesmo em estados patológicos. Indenizar pela metade é responsabilizar a vítima pelo restante. Compete ao perito médico determinar o déficit funcional atual e analisar de que maneira o estado anterior pode concorrer para o dano final (OLIVEIRA; VIEIRA \& CORTE-REAL, 2017). 
Em uma avaliação pericial, ainda referente a situações que envolvem o estado anterior, merecem uma reflexão três questionamentos:

1. O evento traumático não agravou o estado anterior, nem este teve influência negativa sobre as consequências daquele.

2. O estado anterior teve uma influência negativa sobre as consequências do evento traumático.

3. O evento traumático agravou o estado anterior ou exteriorizou uma patologia latente.

Nas situações em que o estado anterior interfere e prejudica a evolução de uma lesão traumática as sequelas serão mais graves (VIEIRA \& QUINTERO, 2008).

O evento traumático pode agravar um estado anterior ou exteriorizar uma patologia latente ou lesões assintomáticas. Um traumatismo pode desencadear sintomas de uma artrose cervical ou lombar, totalmente ignorada ou assintomática, em indivíduo com mais de 50 anos. Outra possibilidade é o traumatismo acelerar ou agravar uma patologia com evolução inevitável e previsível, para uma situação de maior gravidade. São comuns situações que surgem um agravamento definitivo do estado anterior na sequência do traumatismo. O perito deve estar atento para o agravamento de danos sinérgicos, ou seja, quando o dano atinge a mesma estrutura, que são envolvidas na mesma função afetadas por um estado anterior, considerado principalmente sinergias não usuais (perda da mão dominante em um cego, por exemplo) (OLIVEIRA, VIEIRA \& CORTE-REAL, 2017).

Definido o nexo de causalidade o próximo passo na elaboração do relatório pericial é definir a data de cura e consolidação. Após uma sequência de tratamentos, que podem evoluir ao longo de um período de tempo variável, as lesões consequentes de um traumatismo podem evoluir no sentido de cura ou de consolidação. Do ponto de vista médico-legal fala-se em cura quando há uma recuperação total, a vítima não apresenta nenhuma alteração permanente de sua integridade psicofísica. A evolução, no entanto, nem sempre é no sentido da cura, restando alguma afetação permanente anátomo-funcional, psicosensorial ou intelectual. Neste caso falase em consolidação, entendida como um momento em que as lesões deixam de sofrer alterações apreciáveis, se fixam ou estabilizam, sem que a vítima volte a ficar como era antes do evento traumático. Apresentam uma alteração na sua integridade psicofísica de maneira definitiva. Estabelecer a data de cura ou consolidação não é uma tarefa fácil, pois estas datas não são precisas, decorrendo a possibilidade da sua aferição de um acompanhamento clínico regular. Estas datas podem ser estimadas (VIEIRA \& QUINTERO, 2008). 
Fixar a data de consolidação constitui o primeiro objetivo no que se refere a definição de parâmetros periciais. Trata-se de estabelecer um marco que 'demarca' dois terrenos de análise na definição do dano - dano temporário e dano permanente (SÁ, 1992).

Estabelecida a data de cura ou de consolidação, o médico perito define os dois grandes períodos do dano: o período de danos temporários e o período de danos permanentes.

O período de danos temporários é aquele que situa entre a data de produção das lesões e a data da cura ou consolidação dessas lesões. Centrando agora a nossa atenção na avaliação do dano em Direito Civil, um dos parâmetros de dano temporário, praticamente sempre presente é o déficit funcional temporário, entendido como limitações no desempenho de suas atividades da vida diária, familiar e social, independentemente de exercer uma atividade profissional.

Para vítimas que exercem uma atividade profissional deve-se informar a repercussão temporária na atividade profissional. Nestes danos temporários pode-se admitir um déficit total e parcial, descrito habitualmente em número de dias.

Outro parâmetro de dano temporário é o quantum doloris. Refere-se ao sofrimento físico e psíquico do período de dano temporário. Sua avaliação apresenta algumas dificuldades e complexidade, considerando um componente duplamente subjetivo. Habitualmente descrito em uma escala de 7 graus de gravidade crescente (1/7 a 7/7), que evita melindres compreensíveis das vítimas já fragilizadas pela situação que se encontram.

Avaliados os danos temporários, caso tenha havido consolidação, quando a vítima apresenta algum prejuízo definitivo devem-se analisar os danos permanentes.

O déficit funcional permanente (antigamente designado por incapacidade permanente) é um estado deficitário que restou apesar dos cuidados e dos tratamentos realizados, de natureza anátomo-funcional, psicosensorial ou intelectual. Estas alterações da integridade psicofísica são traduzidas em pontos de déficit funcional (antigamente em taxas de incapacidade). Estes pontos são convenções e seus valores resultantes de consensos, muitas vezes resultantes de fatores socioculturais. São valores que tem muito de aleatório e são bastante inadequadas à realidade sequelar de grandes incapacidades. Por isso não basta citar um valor numérico, sendo necessário explicar o significado da pontuação.

Avaliada a alteração da integridade psicofísica, o parâmetro seguinte é definir a repercussão permanente na atividade profissional, descrevendo se as alterações restantes como sequelas do acidente sofrido são compatíveis com o exercício da mesma profissão; se demanda algum esforço acrescido para realizar uma mesma função que exercia antes do evento traumático, se as sequelas são impeditivas do exercício da profissão, sendo compatíveis com 
outras profissões da mesma preparação técnico-profissional ou se a sequela é impeditiva de toda e qualquer profissão.

O dano estético é outro parâmetro do dano, que ainda suscita alguma discussão doutrinária; se sua avaliação deve ser personalizada ou não. Na tentativa de objetivar esta quantificação do dano sugerem sua avaliação de acordo com sua visibilidade. Para traduzir esta avaliação o perito pode recorrer uma escala quantitativa, descrevendo as alterações em uma escala de 7 graus e em gravidade crescente.

A repercussão nas atividades desportivas e lazer (anteriormente designada por prejuízo de afirmação pessoal), reflete como as sequelas vão interferir nas capacidades de ações ligadas às atividades lúdicas e de lazer. A avaliação é semelhante ao dano estético e quantum doloris, utilizando uma escala de 7 graus e em gravidade crescente.

A repercussão nas atividades sexuais é um parâmetro de dano permanente que envolve a limitação total ou parcial do nível de desempenho/gratificação de natureza sexual. Não se contempla aqui a incapacidade de procriar, que é analisada no parâmetro de alteração da integridade psicofísica. Frequentemente subavaliado ou não avaliado. Descrito na mesma escala quantitativa de sete graus de gravidade crescente (VIEIRA \& QUINTERO, 2008).

A concretização desta missão pericial pressupõe uma anamnese precisa e bem realizada, ouvindo atentamente as queixas atribuídas pela vítima às sequelas traumáticas, analisando as circunstâncias do acidente e de seu mecanismo, buscando os elementos probatórios em questões médicas, realizando um exame clínico pericial exaustivo da região corporal traumatizada. $\mathrm{O}$ perito deve realizar uma reflexão crítica cuidadosa e imparcial quanto ao nexo de causalidade entre o evento informado e as sequelas constatadas e em seguida estimar a data de cura ou consolidação que demarcará os danos temporários e permanentes com seus diversos parâmetros. A missão será concluída com a elaboração do laudo pericial onde deve constar um capítulo de discussão destinado a explicar ao destinatário do processo a opinião do médico de forma a fundamentar claramente a síntese final representada pelas conclusões (VIEIRA\& QUINTERO, 2008).

Nota-se claramente que a metodologia proposta, com seus conceitos bem delimitados e definidos permite sua universalização, tendo em conta sua consonância com os conceitos e preceitos da Classificação Internacional de Funcionalidades Incapacidade e Saúde (CIF), que pertence à "família" das classificações internacionais desenvolvida pela Organização Mundial da Saúde (OMS) para aplicação em vários aspectos da saúde, como por exemplo, proporcionar 
uma linguagem unificada e padronizada assim como uma estrutura de trabalho para a descrição da saúde e de estados relacionados com a saúde, objetivo geral da CIF (OMS / CIF, 2003).

Esta realidade médico-legal portuguesa, que apresenta uma metodologia estruturada para a elaboração de um laudo pericial e que tem sintonia com a avaliação do dano à pessoa proposta para a União Europeia pela CEREDOC, nos traz novas perspectivas quanto ao que desejamos que seja a avaliação destes danos no Brasil.

\section{CONSIDERAÇÕES FINAIS}

Avaliar um dano corporal exige uma preparação médico-legal neste domínio, que a simples formação em qualquer especialidade clínica, por melhor que tenha sido não confere. Apresentamos uma metodologia para avaliação de um dano à pessoa, uma vez que no Brasil deparamo-nos com uma quase ausência de normas quanto à realização de perícias no âmbito do Direito Civil e do Direito do Trabalho, o que pode causar discrepâncias na atribuição de indenização.

Ainda nos deparamos com laudos que contém somente resposta de quesitos em perícias médicas de avaliação dos danos corporais. Existem médicos que desconhecem por completo as metodologias e especialidades da peritagem da avaliação do dano à pessoa. Este ato não é competência exclusiva do especialista em Medicina Legal, pode ser executado por muitos outros especialistas, de varias áreas clínicas, desde que detentores de preparação adequada neste dominio. Esta realidade médico-legal portuguesa apresenta novas perspectivas quanto ao que desejamos que seja a avaliação destes danos no Brasil.

Parece-nos que os modelos seguidos em Portugal, com as devidas adaptações à realidade brasileira, sobretudo aos aspectos legais, poderiam constituir um importante contributo à promoção da qualidade das perícias efetuadas no Brasil, orientando-as melhor para o objetivo que se propõem servir (SILVA \& MAGALHÃES, 2011).

Fica agora a faltar outros cursos de aperfeiçoamento para médicos peritos e demais especialistas clínicos que tenham interesse nesta matéria, expectativa que vem sendo concretizada pelos esforços já mencionados acima e graças a parcerias realizadas entre instituições de ambos os países. 


\section{REFERÊNCIAS}

ESTEVAN, A. Los accidentes de automóvil: una matanza calculada. Madrid: Instituto Juan de Herrera, 2001. Disponível em: https://bit.ly/2Er4Xgt. Acesso em: 19 dez 2018.

GUIMARÃES CARDOSO, Mariana et al. Caracterização das ocorrências de acidentes de trabalho graves. Arquivos de Ciências da Saúde, São José do Rio Preto - SP, v. 23, n. 4, p. 83-88, dez. 2016. Disponível em: https://bit.ly/2VHcspd. Acesso em: 10 jan 2019.

JORGE M.H.P.M.; KOIZUMI M.S. Acidentes de trânsito no Brasil: um atlas de sua distribuição. Associação Brasileira de Medicina de Tráfego, São Paulo, v. 26, n. 1, p. 52-58, 2008 .

LAMBERT-FAIVRE, Y; PORCHY-SIMON, S. Droit du dommagecorporel: Systémes d'indemnisation. Paris: Dalloz, 2011.

LUCAS, P. Le Dommage Corporel et l'Expertise. Bruxelas: Anthemis, 2009.

MAGALHÃES, T.M.S. Estudo tridimensional do dano corporal: Lesão, função e situação (sua aplicação médico-legal). Coimbra: Almedina, 1998.

MAGALHÃES T.; VIEIRA D.N. Recomendações gerais para a realização de relatórios periciais de clínica forense no âmbito do direito civil. Revista Portuguesa do Dano Corporal, v.20, p.70-90, 2010.

MARÍN L.; QUEIROZ M. S. A atualidade dos acidentes de trânsito na era da velocidade: uma visão geral. Cad. Saúde Pública, Rio de Janeiro v.16, p. 7-21, 2000.

OLIVEIRA, C.; VIEIRA, D.N.; CORTE-REAL, F. Nexo de causalidade e estado anterior na avaliação médico-legal do dano corporal. Coimbra: Imprensa da Universidade de Coimbra, 2017.

OMS - Organização Mundial da Saúde. CIF: Classificação Internacional de Funcionalidade, Incapacidade e Saúde. Trad. do Centro Colaborador da Organização Mundial da Saúde para a Família de Classificações Internacionais. São Paulo: EDUSP; 2003.

SÁ, O. Clínica Médico-Legal da Reparação do Dano Corporal em Direito Civil. Coimbra: APADAC, 1992.

SILVA, W.F.M. Avaliação do dano corporal no Brasil: O caso dos acidentes de viação. 06/03/2012. 58 fls. Dissertação (Mestrado em Ciências Forenses). Universidade do Porto. Cidade do Porto, 06/03/2012.

SILVA, W.F.M.; MAGALHÃES, T.M.S. Avaliação do dano corporal no Brasil: O caso dos acidentes de viação. Revista Portuguesa do Dano Corporal, Coimbra, v.22, p.99-132, 2011. Disponível em: https://bit.ly/2Jw1yRL. Acesso em: 10 dez 2018.

SIMONIN, C. Médicine Légale Judiciaire. 2 ed. Paris: Librairie Maloine, 1947.

ROUSSEAU, C. L'evolution de la doctrine em matière d'evaluation du dommage corporel en droit commun. Revue Française du dommage corporel, Paris, v.9, n.3, p. 237-248. 1983. 
VIEIRA D.N. A “missão" de avaliação do dano corporal em direito civil. Sub Júdice, v.17, n.1, p.23-30, 2000.

VIEIRA, D.N.; QUINTERO, J.A. Aspectos práticos da avaliação do dano corporal em Direito Civil. Coimbra:Imprensa da Universidade de Coimbra, 2008. 